\title{
Paracetamol degradation in aqueous solution by non-thermal plasma*
}

\author{
Yasmine Baloul $^{1}$, Olivier Aubry ${ }^{1, a}$, Hervé Rabat ${ }^{1}$, Cyril Colas ${ }^{2,3}$, Benoît Maunit ${ }^{2}$, and Dunpin Hong ${ }^{1}$ \\ ${ }^{1}$ GREMI, UMR 7344, CNRS/Université d'Orléans, 14 rue d'Issoudun, BP 6744, 45067 Orléans Cedex 2, France \\ ${ }^{2}$ ICOA, UMR 7311, CNRS/Université d'Orléans, Pôle Chimie, rue de Chartres, BP 6759, 45067 Orléans Cedex 2 , France \\ ${ }^{3}$ CBM, UPR 4301, CNRS, rue Charles Sadron, CS 80054, 45071 Orléans Cedex 2, France
}

Received: 14 December 2016 / Received in final form: 20 January 2017 / Accepted: 10 July 2017

(c) EDP Sciences 2017

\begin{abstract}
This study deals with paracetamol degradation in water using a non-thermal plasma (NTP) created by a dielectric barrier discharge (DBD). The effects of the NTP operating conditions on the degradation were studied, showing that the treatment efficiency of the process was highly dependent on the electrical parameters and working gas composition in the reactor containing the aqueous solution. A conversion rate higher than $99 \%$ was reached with an energy yield of $12 \mathrm{~g} / \mathrm{kWh}$. High resolution mass spectrometry (HRMS) measurements showed that the main species produced in water during the process were nitrogen compounds, carboxylic acids and aromatic compounds.
\end{abstract}

\section{Introduction}

Pharmaceutical substances such as paracetamol are frequently present in groundwater, and present a long-term risk for the environment and health [1]. Advanced oxidation processes (AOPs) generating many oxidizing species such as $\mathrm{O}, \mathrm{O}_{3}, \mathrm{OH}^{\bullet}$ and $\mathrm{H}_{2} \mathrm{O}_{2}$ have been tested for the degradation of these drug residues [2-4]. AOPs involve several techniques such as $\mathrm{TiO}_{2}$ catalysis, Fenton's reaction and non-thermal plasmas (NTP) [5,6]. AOPs with NTP have already been applied to the treatment of pharmaceutical compounds in aqueous media $[6,7]$ and showed a high potential. In this study, a NTP created by a dielectric barrier discharge (DBD) was used as an AOP for the degradation of paracetamol in liquid. To optimize this process, paracetamol degradation was performed with several values of the electrical parameters of the discharge and several working gas compositions and the energy yields were determined. The main by-products from paracetamol degradation were identified by high resolution mass spectrometry (HRMS). In the next section, the experimental setup and the measurement techniques including the high-resolution mass spectrometer are presented. The results are presented in Section 3 and the Section 4 concludes the paper.

\footnotetext{
${ }^{a}$ e-mail: olivier.aubry@univ-orleans.fr

* Contribution to the topical issue "The 15th International Symposium on High Pressure Low Temperature Plasma Chemistry (HAKONE XV)", edited by Nicolas Gherardi and Tomáš Hoder
}

\section{Experimental setup and methodology}

The schematic diagram of the experimental setup is given in Figure 1.

The plasma reactor was a multiple needle-to-plate configuration and was described in a previous paper [8]. Briefly, the needle-to-plate device was placed inside a vessel made of Polyvinyl chloride (PVC) where the working gas can be controlled (composition and total flow rate). High voltage was applied to the 12 capillary needles (0.4 $\mathrm{mm}$ in inner diameter), while the grounded electrode was a copper film deposited on a dielectric epoxy plate that was in contact with the liquid [8]. The distance between the electrodes and the surface of the liquid can be adjusted from 0 to $10 \mathrm{~mm}$.

In this work, the electrode to liquid gap was $5 \mathrm{~mm}$. The volume of the treated solution was $40 \mathrm{~mL}$ of tap water with an initial concentration of paracetamol of $25 \mathrm{mg} / \mathrm{L}$.

The discharges were generated at the tip of the needles above the liquid thanks to a high voltage square waveform with a frequency of several hundred Hertz. As expected, the discharge current was composed of multiple fast pulses, especially during the rising and the falling of the square voltage waveform. The current peaks were on the order of a few tens of $\mathrm{mA} \mathrm{[8].} \mathrm{Electrical} \mathrm{measurements}$ were performed using high-voltage (PE20 KV Lecroy ${ }^{\circledR}$ ) and current (CTC5 Magnelab ${ }^{\circledR}$ ) probes and were recorded with an oscilloscope (DPO 3054 Tektronic ${ }^{\circledR}$ ). To determine the dissipated power, a capacitor was inserted into the discharge circuit enabling the use of the Lissajous method [9]. Figure 2 shows a plot of the Lissajous curve. 


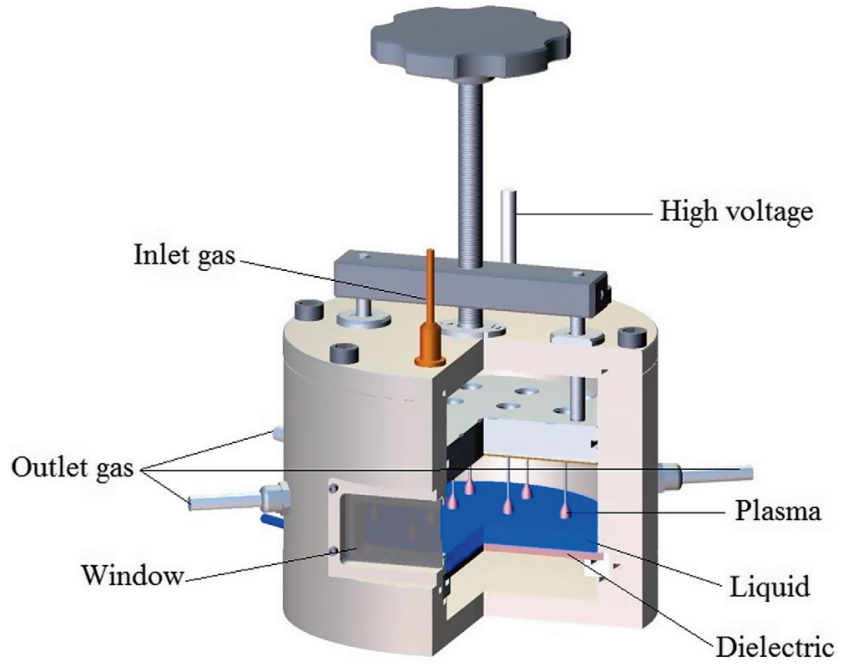

Fig. 1. Sketch of the multiple needle-to-plate experimental apparatus for the drug polluted water treatment.

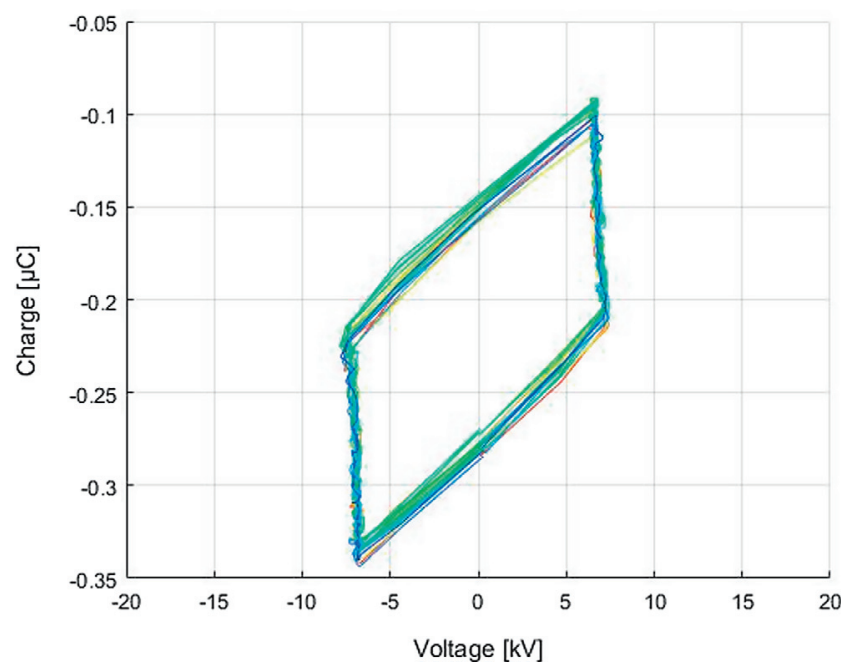

Fig. 2. Lissajous curve (discharges in air with a mass-flow rate of $100 \mathrm{sccm}$, with $U= \pm 6.8 \mathrm{kV}, f=500 \mathrm{~Hz}$, electrode-liquid gap $=5 \mathrm{~mm}$ ).

This method was used to measure the power consumption for each operating condition.

To quantify the paracetamol concentration in the solution, analyses were performed using a UV-Visible absorption spectrophotometer (Cary 60 UV-Vis Agilent Technologies $\left.{ }^{\circledR}\right)$. To estimate the concentrations of $\mathrm{H}_{2} \mathrm{O}_{2}$, $\mathrm{NO}_{2}^{-}, \mathrm{NO}_{3}^{-}$, semi-quantitative test strips QUANTOFIX ${ }^{\circledR}$ were used, and measurements were made every 15 min during the $1 \mathrm{~h}$ of treatment. The degradation products were analyzed by HRMS with a Q-TOF maXis mass spectrometer (Bruker ${ }^{\circledR}$ ) [10] provided by the French "Fédération de Recherche" FR2708. For the HRMS measurements, the solvent was a 35:65 mixture of water (with or without $0.1 \% \mathrm{HCOOH}$ ) and acetonitrile, at a flow rate of $200 \mu \mathrm{L} / \mathrm{min}$. An electrospray ionization (ESI) source was used with a suitable differential potential for the capillary in the positive ionization mode $(4.5 \mathrm{kV})$ and negative one $(3.4 \mathrm{kV})$. For both modes, nebulizing and drying gas were set at respectively 0.6 bar and $7 \mathrm{~L} / \mathrm{min}$ and the drying gas was heated to $200{ }^{\circ} \mathrm{C}$. The injection volume was set at $1 \mu \mathrm{L}$. Mass spectra were recorded at $1 \mathrm{~Hz}$ in the range of 50-650 for mass to charge ratio $(\mathrm{m} / z)$. Chemical formulae were generated using the SmartFormula algorithm from DataAnalysis 4.0 software (Bruker $\left.{ }^{\circledR}\right)$. In order to reduce ion suppression in our mass spectrometry measurement, FIA (flow injection analysis) was used instead of liquid chromatography (LC), since with LC, small carboxylic acids are eluted in the dead volume with rich aqueous solvent, which is more difficult to desolvate.

To identify the species produced by the plasma treatment, a three-step analysis processing was performed for each operating condition: firstly, the spectrum of water without paracetamol submitted to plasma treatment was analyzed in order to define a baseline composed of the ions coming from the plasma processing and HRMS system. Then a solution of paracetamol prior to plasma treatment was analyzed to identify in-source fragmentation ions coming from the paracetamol molecule. Finally, the samples of paracetamol treated by plasma were analyzed and the spectrum of water without paracetamol submitted to plasma was subtracted as background. The obtained spectra can then be exploited to identify the degradation products.

\section{Results and discussion}

\subsection{Effects of operating conditions}

This section presents the experimental results concerning the conversion rate, $\tau$, and the energy yield, EY (in $\mathrm{g} / \mathrm{kWh}$ ), of paracetamol degradation calculated with equations (1) and (2), respectively. $C_{0}, C_{t}$ are concentrations (in $\mathrm{g} / \mathrm{L}$ ) of paracetamol in the solution at the beginning and at the end of the time interval $\Delta t(\mathrm{~h})$, $V$ is the volume of the solution (L) and $P$, the power consumed $(\mathrm{kW})$.

$$
\begin{aligned}
\tau & =\frac{C_{0}-C_{t}}{C_{0}} \times 100, \\
\mathrm{EY} & =\frac{\left(C_{0}-C_{t}\right) \times V}{\Delta t \times P} .
\end{aligned}
$$

In a previous paper [8], it was shown that depending on the applied voltage, there were three different discharge regimes, namely corona, streamer and spark regimes. Spectroscopy measurements showed that the production of $\mathrm{OH}$ was much higher in the spark regime. However, the spark regime may disrupt the operation of the reactor, causing water vapor on the reactor wall, and needle ignition problems [8]. The streamer regime was therefore used in the present study. It was also shown that, within the streamer regime, a better conversion rate of paracetamol was obtained when the applied voltage was high, for the same treatment time. 


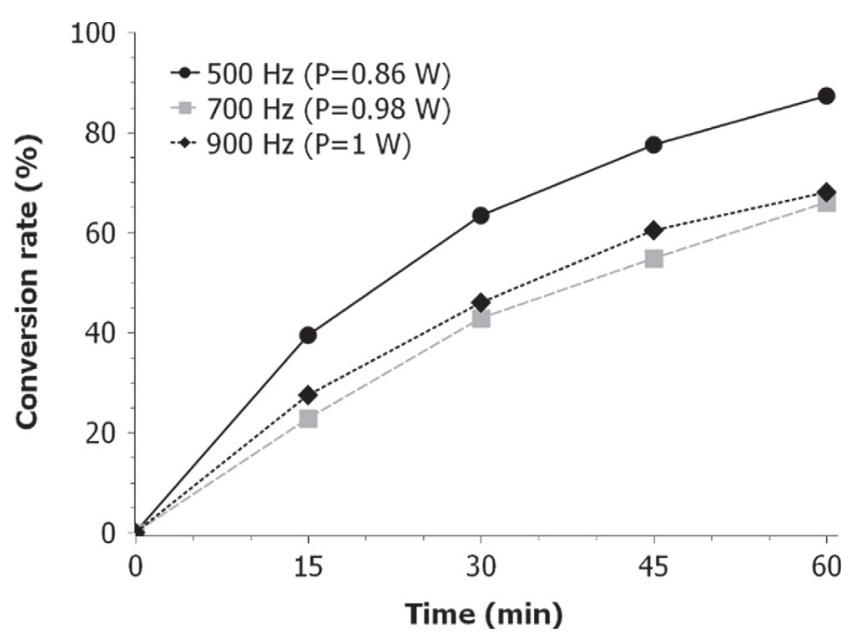

Fig. 3. Paracetamol conversion rates as a function of time for three discharge frequencies $(U= \pm 6.8 \mathrm{kV}$; electrode-liquid gap $=5 \mathrm{~mm}$; air flow rate $=100 \mathrm{sccm})$.

In this work, treatments were carried out with discharges in air at several frequencies of the power supply of a fixed voltage amplitude, namely $\pm 6.8 \mathrm{kV}$. In our specific conditions, when the frequency exceeded $900 \mathrm{~Hz}$, the discharge regime oscillated between streamer and spark; the measurements for frequencies $>900 \mathrm{~Hz}$ are not reported here. Figure 3 shows the conversion rate as a function of the treatment time for three frequencies: 500, 700 and $900 \mathrm{~Hz}$. The corresponding consumed power was $0.86,0.98$ and $1 \mathrm{~W}$ respectively. These values are not proportional to the power supply frequency as is generally observed in other DBD studies [11]. The nonlinear dependence between power dissipation and frequency seemed to indicate the continuous change of the discharge regime when the frequency rose from $500 \mathrm{~Hz}$ to $900 \mathrm{~Hz}$.

According to the three curves in Figure 3, a rise in frequency from $500 \mathrm{~Hz}$ to $900 \mathrm{~Hz}$ led to a decrease in the conversion rate with a rise in the consumed power and consequently a decrease in EY. Thus, in air (flow rate of $100 \mathrm{sccm}$ ), the optimal electrical parameters to obtain high conversion rates and high EY were an applied voltage of $\pm 6.8 \mathrm{kV}$ with a frequency of $500 \mathrm{~Hz}$ for an electrodeliquid gap of $5 \mathrm{~mm}$.

The effects of the composition of the inlet gas on paracetamol degradation were studied maintaining the frequency at $500 \mathrm{~Hz}$ (Fig. 4). The working voltage was $\pm 5 \mathrm{kV}$ for the mixture $10 \% \mathrm{O}_{2}+90 \% \mathrm{Ar}, \pm 3.6 \mathrm{kV}$ for the mixture $10 \%$ air $+90 \% \mathrm{Ar}$ and $\pm 6.8 \mathrm{kV}$ for $100 \%$ air. These working voltage values were the maximum values to maintain the discharge in streamer regime for each corresponding composition. Figure 4a shows the conversion rates for various inlet gas mixtures as a function of the treatment time. These curves show that the composition of the inlet gas plays an important role in paracetamol degradation. The highest conversion rate was obtained with the $10 \% \mathrm{O}_{2}+90 \%$ Ar mixture. The working gas used in this study always contained $\mathrm{O}_{2}$ since the presence of $\mathrm{O}_{2}$ enables the generation of oxidizing species such as

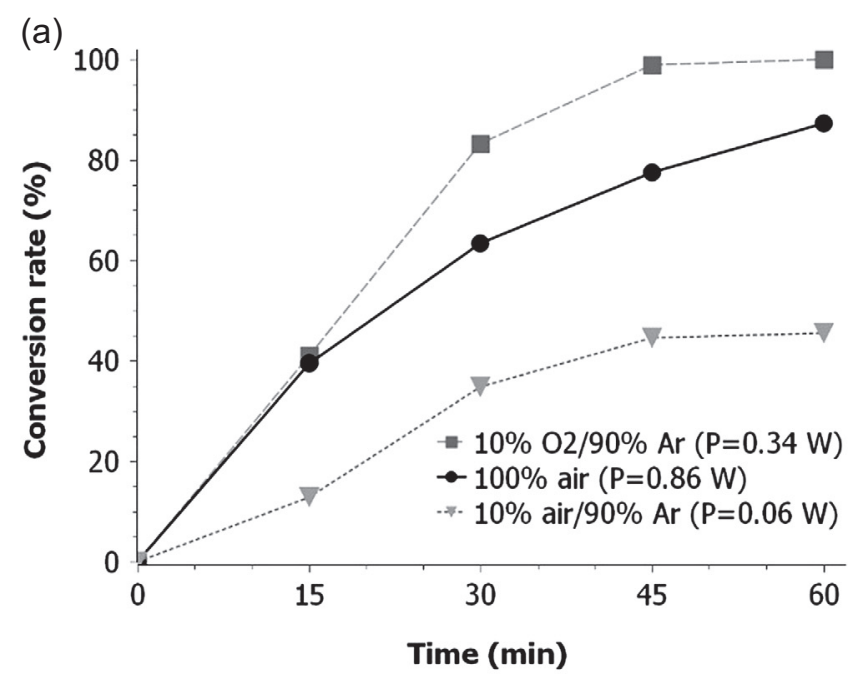

(b)

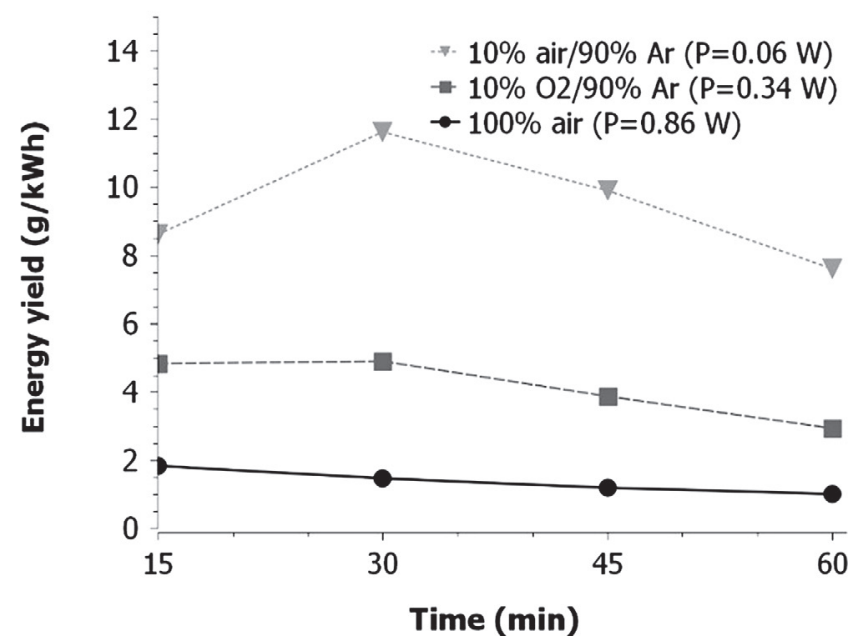

Fig. 4. (a) Paracetamol conversion rates and (b) energy yields as a function of time.

$\mathrm{O}$ or $\mathrm{O}_{3}$ in the gas phase and also $\mathrm{OH}^{\bullet}$ in the liquid phase to degrade the pollutant; in the absence of oxygen in the injected gas, no paracetamol degradation was observed [8].

As shown in Figure 4b, the energy yield of the process depended on the nature of the working gas, since the electric power consumed strongly depends on the injected gas. With the mixture $10 \% \mathrm{O}_{2}+90 \% \mathrm{Ar}$, we obtained the highest $\tau$, but its EY was lower than that of the mixture $10 \%$ air $+90 \%$ Ar because of a higher power consumption. The advantage of combining argon with $\mathrm{O}_{2}$ is that the discharge can be generated more easily and a lower applied voltage can be used, thanks to a lower breakdown voltage [12].

Although the plasma process used in this work is not yet fully optimized, our experimental conditions produced a high rate of paracetamol degradation with an energy yield in the range of $1-12 \mathrm{~g} / \mathrm{kWh}$. Panorel et al. [7] obtained an energy yield between 14 and $18 \mathrm{~g} / \mathrm{kWh}$, which is a little higher than our results. 
The European Physical Journal Applied Physics

Table 1. Concentration ranges of $\mathrm{NO}_{3}^{-}, \mathrm{NO}_{2}^{-}, \mathrm{H}_{2} \mathrm{O}_{2}$ in the liquid after 60 min of treatment.

\begin{tabular}{lccc}
\hline & {$\left[\mathrm{NO}_{3}^{-}\right] \mathrm{mg} / \mathrm{L}$} & {$\left[\mathrm{NO}_{2}^{-}\right] \mathrm{mg} / \mathrm{L}$} & $\mathrm{H}_{2} \mathrm{O}_{2} \mathrm{mg} / \mathrm{L}$ \\
\hline $90 \% \mathrm{Ar}+10 \% \mathrm{O}_{2}$ & 0 & 0 & $10-25$ \\
$90 \% \mathrm{Ar}+10 \%$ air & $25-50$ & $5-10$ & $10-25$ \\
$100 \%$ Air & $50-100$ & $0-1$ & $10-25$ \\
\hline
\end{tabular}
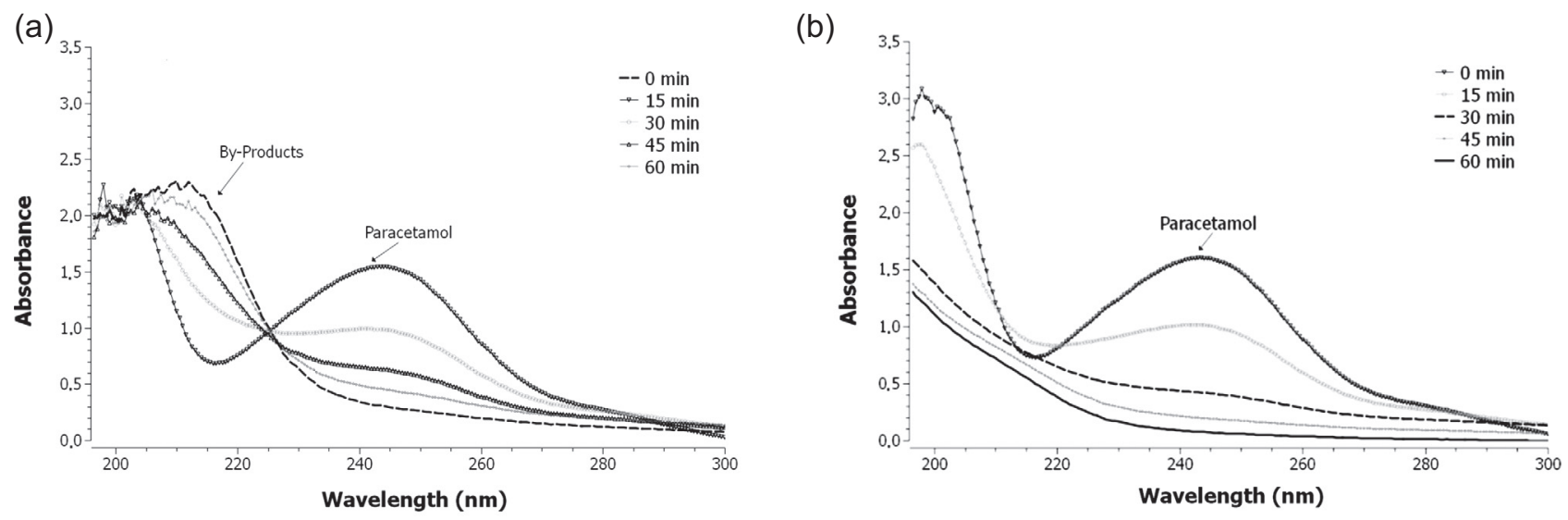

(c)

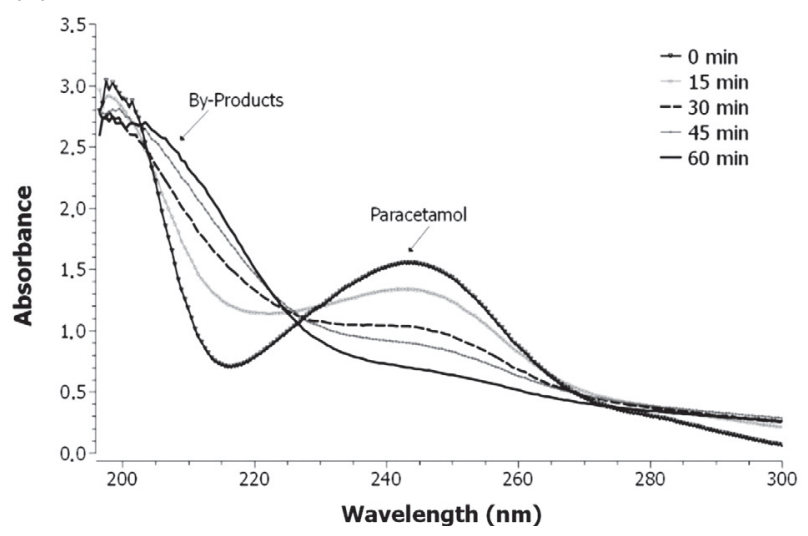

Fig. 5. Absorption spectra for three compositions of the working gas with a total flow rate of 100 sccm. (a) $100 \%$ air with $U= \pm 6.8 \mathrm{kV}$; (b) $90 \% \mathrm{Ar}+10 \% \mathrm{O}_{2}$ with $U= \pm 5 \mathrm{kV}$; (c) $90 \% \mathrm{Ar}+10 \%$ air with $U= \pm 3.6 \mathrm{kV}$.

\subsection{Generated products}

The UV absorption spectra presented below show that $\mathrm{NO}_{3}^{-}$, and $\mathrm{NO}_{2}^{-}$were present in the treated liquids. Their concentrations were measured with QUANTOFIX ${ }^{\circledR}$ quantitative test strips every $15 \mathrm{~min}$ during the $1 \mathrm{~h}$ of treatment. $\mathrm{pH}$ was also measured for each sample. The results obtained after $60 \mathrm{~min}$ of treatment are displayed in Table $1 . \mathrm{H}_{2} \mathrm{O}_{2}$ was also measured since it is a well-known oxidizing species which can react non-selectively with organic pollutants [13]. In our experiments, the increase in treatment duration led to a rise in $\mathrm{H}_{2} \mathrm{O}_{2}$ concentration; and at a given time, its concentration was in the same range whatever the inlet gas, as indicated in Table 1. In presence of $\mathrm{O}_{2}$ and $\mathrm{N}_{2}$, the concentrations of $\mathrm{NO}_{3}^{-}$ and $\mathrm{NO}_{2}^{-}$increased with the treatment time, reaching ranges of $50-100$ and $5-10 \mathrm{mg} / \mathrm{L}$, respectively, after $1 \mathrm{~h}$ of<smiles>CC(=O)Nc1ccc(O)cc1</smiles>

Fig. 6. Chemical structure of paracetamol (acetyl-paraaminophenol) $\mathrm{C}_{8} \mathrm{H}_{9} \mathrm{NO}_{2}(M=151 \mathrm{~g} / \mathrm{mol})$.

treatment. The production of $\mathrm{NO}_{3}^{-}$and $\mathrm{NO}_{2}^{-}$did not seem to be linked to the degradation of paracetamol since in the $\mathrm{Ar}-\mathrm{O}_{2}$ mixture, these species were not detected despite the high conversion rate of paracetamol.

Figure 5 shows the absorption spectra of the treated liquids for different treatment times, and for various inlet gas compositions. The absorption band centered at $243.9 \mathrm{~nm}$ is due to paracetamol. The absorption coefficient 
Y. Baloul et al.: Paracetamol degradation in aqueous solution by non-thermal plasma

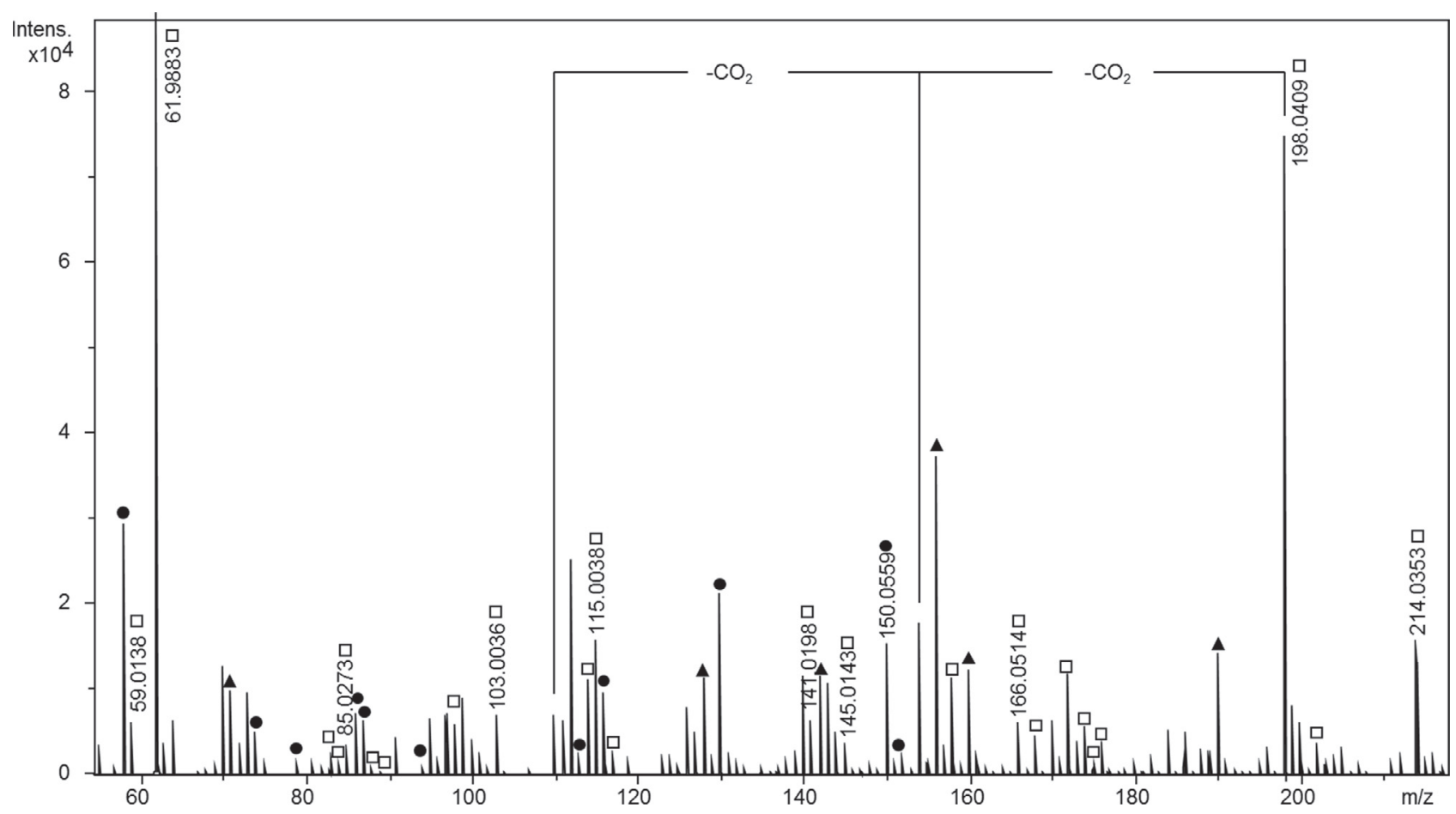

Fig. 7. Paracetamol mass spectrum in ESI negative mode after 60 min of treatment: " $\square$ " products generated in paracetamol treatment, "•" paracetamol and paracetamol fragments in the ionization source, "А" fragments detected in water with plasma treatment (without paracetamol).

at $243.9 \mathrm{~nm}$ was used to determine the paracetamol concentration. With treatment, an absorption band around $210 \mathrm{~nm}$ appeared, indicating the presence of $\mathrm{NO}_{3}^{-}$and $\mathrm{NO}_{2}^{-}$in the treated liquids [14]. As this absorption band is not isolated, however, it could not be used to quantify the concentrations of $\mathrm{NO}_{3}^{-}$and $\mathrm{NO}_{2}^{-}$When the paracetamol was treated with the $\mathrm{Ar}+\mathrm{O}_{2}$ mixture (Fig. 5b), the absorption band around $210 \mathrm{~nm}$ disappeared, indicating that this absorption band was linked to the presence of $\mathrm{N}_{2}$ in the inlet gas.

Due to the perturbation of the nitrite and nitrate molecules and also other cyclic by-products, the absorption at $243.9 \mathrm{~nm}$ is not due to paracetamol alone [15]. The paracetamol concentrations deduced from the absorption at $243.9 \mathrm{~nm}$ were therefore overestimated. Consequently, the energy yields given in this paper were underestimated.

In order to determine the by-products in the liquid phase, HRMS measurements were performed on the paracetamol solution after $60 \mathrm{~min}$ of treatment and provided mass spectra. When a spectrum was obtained in ESI negative mode, the mass to charge ratio $(\mathrm{m} / \mathrm{z})$ peak corresponded to a molecule from which a proton had been removed. For instance, the molar mass of paracetamol whose chemical structure is given in Figure 6, is $151 \mathrm{~g} / \mathrm{mol}$, so the $m / z$ peak at 150.0559 corresponded to the presence of paracetamol, in negative mode.

Figure 7 shows an experimental mass spectrum of paracetamol after plasma treatment. There are a large number of peaks in the spectrum, and the identification of these peaks required the analysis of several spectra such as the spectrum of the paracetamol solution without plasma treatment and those of water as indicated in Section 2. Careful analysis of these spectra enabled the identification of the majority of the peaks. Firstly, there is a peak at $m / z 61.9883$ which corresponds to the nitrate ion $\left(\mathrm{NO}_{3}^{-}\right)$. Secondly, there is a small peak at $\mathrm{m} / z 150.0559$ corresponding to the residual paracetamol. Thirdly, the peak at $m / z 198.0409$ corresponds to the ion $\mathrm{C}_{8} \mathrm{H}_{8} \mathrm{NO}_{5}^{-}$. This ion was fragmented in the mass spectrometer into smaller fragments at $m / z 154.0505$ and 110.0608 by losing one and two $\mathrm{CO}_{2}$ molecules; these fragmentations were verified by tandem Mass Spectrometry (MS/MS) experiments, indicating that this compound corresponds to a dicarboxylic acid molecule. Fourthly, we detected nine other peaks, among which eight carboxylic acids; the $m / z$ values and inferred compounds are listed in Table 2. These products have already been observed during paracetamol treatment performed by other AOPs $[12,15-19]$ and also in a process using NTP [3]. Moreover Marotta et al. [20] already demonstrated the formation of carboxylic acids in their experiments concerning the treatment of phenol by a non-thermal plasma.

Concerning the identification of the other small peaks, the analysis of several spectra from different samples made it possible to identify the other degradation products due to the treatment; these peaks are indicated by " $\square$ " in the spectrum. A list of 35 compounds was established in the negative and positive modes and the study of the chemical pathways leading to these compounds is ongoing. 
The European Physical Journal Applied Physics

Table 2. Main degradation products identified by HRMS.

\begin{tabular}{|c|c|c|c|}
\hline \multirow{2}{*}{$\begin{array}{c}\text { Experimental } \\
m / z\end{array}$} & \multirow[t]{2}{*}{ Ion formula } & \multicolumn{2}{|c|}{ Hypothetical molecule } \\
\hline & & Structural formulas & Name \\
\hline 59.0138 & $\mathrm{C}_{2} \mathrm{H}_{3} \mathrm{O}_{2}^{-}$ & & Acetic acid \\
\hline 85.0273 & $\mathrm{C}_{4} \mathrm{H}_{5} \mathrm{O}_{2}$ & O & Crotonic acid \\
\hline 103.0036 & $\mathrm{C}_{3} \mathrm{H}_{3} \mathrm{O}_{4}$ & $\mathrm{O}$ & Malonic acid $[15,16]$ \\
\hline 115.0038 & $\mathrm{C}_{4} \mathrm{H}_{3} \mathrm{O}_{4}^{-}$ & O & Maleic acid \\
\hline 141.0198 & $\mathrm{C}_{6} \mathrm{H}_{5} \mathrm{O}_{4}^{-}$ & 0 & Muconic acid \\
\hline 145.0143 & $\mathrm{C}_{5} \mathrm{H}_{5} \mathrm{O}_{5}^{-}$ & & Acetonedicarboxylic acid \\
\hline 166.0514 & $\mathrm{C}_{8} \mathrm{H}_{8} \mathrm{NO}_{3}^{-}$ & & Hydroxy-4-(N-acetyl)-aminophenol [12] \\
\hline 198.0409 & $\mathrm{C}_{8} \mathrm{H}_{8} \mathrm{NO}_{5}^{-}$ & & {$[15,17]$} \\
\hline 214.0353 & $\mathrm{C}_{8} \mathrm{H}_{8} \mathrm{NO}_{6}^{-}$ & & {$[15]$} \\
\hline
\end{tabular}


The peaks marked by " $\boldsymbol{\Delta}$ " were found in the analysis of the pure water solution after plasma treatment, those marked by "•" were already observed in the paracetamol solution without treatment and no further investigation was performed on these ions. Finally, the other peaks not marked by a symbol have not yet been identified.

\section{Conclusion}

In this study on the treatment of paracetamol in aqueous solution by non-thermal plasma, the highest conversion rate close to $99 \%$ was obtained for a gas mixture of $\mathrm{O}_{2}-\mathrm{Ar}$ with an energy yield of about $5 \mathrm{~g} / \mathrm{kWh}$. The best energy yield of $12 \mathrm{~g} / \mathrm{kWh}$ was obtained for a gas mixture of air-Ar. This study showed that the energy yield of the process is highly dependent on the experimental conditions, in particular the power consumption and the composition of the working gas. Regarding the role of gas composition, we note that the presence of $\mathrm{O}_{2}$ is necessary in the process to remove paracetamol in aqueous phase [8].

It also showed that, as expected, carboxylic acids and aromatic compounds are the main degradation products of paracetamol in the liquid, which also contains nitrites, nitrates produced also in liquid phase. The perspectives of this work are the study of the influence of the concentration and the volume of the solution, a comparison of this process with other ones, for instance with the use of a post-discharge, as an ozone generator and the study of the main pathways leading to the generation of the by-products detected.

The authors thank the Région Centre-Val de Loire for their financial support of the TREMEMAP project.

\section{References}

1. D. Kolpin, M. Skopec, M. Meyer, E. Furlong, S. Zaugg, Sci. Total Environ. 328, 119 (2004)
2. B.R. Locke, M. Sato, P. Sunka, M.R. Hoffmann, J.-S. Chang, Ind. Eng. Chem. Res. 45, 882 (2006)

3. K. Ikehata, N.J. Naghashkar, M. Gamal El-Din, Ozone: Sci. Eng. 28, 353 (2006)

4. C.A. Lutterbeck, M.L. Wilde, E. Baginska, C. Leder, Ê.L. Machado, K. Kümmerer, Sci. Total Environ. 527-528, 232 (2015)

5. J.O. Tijani, O.O. Fatoba, G. Madzivire, L.F. Petrik, Water Air Soil Pollut. 225, 2102 (2014)

6. M. Magureanu, D. Piroi, N.B. Mandache, V. David, A. Medvedovici, C. Bradu, V.I. Parvulescu, Water Res. 45, 3407 (2011)

7. I. Panorel, S. Preis, I. Kornev, H. Hatakka, M. LouhiKultanen, Ozone: Sci. Eng. 35, 116 (2013)

8. Y. Baloul, H. Rabat, D. Hong, S. Chuon, O. Aubry, I.J. PEST 10, 102 (2016)

9. Z. Falkenstein, J.J. Coogan, J. Phys. D: Appl. Phys. 30, 817 (1997)

10. H. Belghit, C. Colas, S. Bristeau, C. Mouvet, B. Maunit, Int. J. Environ. Anal. Chem. 95, 93 (2015)

11. B. Dong, J.M. Bauchire, J.M. Pouvesle, P. Magnier, D. Hong, J. Phys. D: Appl. Phys. 41, 155201 (2008)

12. J. Park, I. Henins, H.W. Herrmann, G.S. Selwyn, J. Appl. Phys. 89, 15 (2001)

13. M. Magureanu, N.B. Mandache, V.I. Parvulescu, Plasma Chem. Plasma Process. 27, 589 (2007)

14. J.S. Oh, S. Ito, H. Furuta, A. Hatta, in Proc. of 22nd ISPC, Belgium, 2015, http://www.ispc-conference. org/ispcproc/ispc22/0-14-5.pdf

15. E. Pretsch, P. Buhlmann, M. Badertscher, Structure Determination of Organic Compounds (Springer Berlin Heidelberg, 2009)

16. J. Zeng, B. Yang, X. Wang, Z. Li, X. Zhang, L. Lei, Chem. Eng. J. 267, 282 (2015)

17. R. Andreozzi, V. Caprio, R. Marotta, D. Vogna, Water Res. 37, 993 (2003)

18. M. Torun, Ö. Gültekin, D. Şolpan, O. Güven, Environ. Technol. 36, 970 (2015)

19. E. Moctezuma, E. Leyva, C.A. Aguilar, R.A. Luna, C. Montalvo, J. Hazard. Mater. 243, 130 (2012)

20. E. Marotta, M. Schiorlin, X. Ren, M. Rea, C. Paradisi, Plasma Processes Polym. 8, 867 (2011) 